\title{
The Role of Biological Sex in Severely Traumatized Patients on Outcomes
}

\author{
A Matched-pair Analysis
}

\author{
Heiko Trentzsch, MD, ${ }^{*}$ Rolf Lefering, PhD, $\dagger$ Ulrike Nienaber, MSc, $\ddagger$ Robert Kraft, MD, $\S$ Eugen Faist, MD, FACS, $\uparrow$ \\ and Stefan Piltz, MD
}

Objective: Analyze sex differences in TraumaRegister DGU (TR-DGU).

Background: Sex differences are considered to influence trauma outcomes. However, clinical study results are controversial.

Methods: Of 29,353 prospectively recorded cases of TR-DGU, we included primary trauma room admissions with Injury Severity Score of 9 or more into the analysis. Pairs $(n=3887)$ were formed from 1 male and 1 female according to age, mechanism, injury severity by Abbreviated Injury Scale (for head, thorax, abdomen, extremities), and occurrence of prehospital shock. Biochemical markers, treatment modalities, length of stay, and outcome (multiple organ failure, sepsis, mortality rates) were assessed. Statistical significance was accepted at $P<0.05$. Odds ratios (ORs) are given with $95 \%$ confidence interval (CI).

Results: Females had less multiple organ failure [OR: 1.18 (95\% CI, 1.05$1.33) ; P=0.007$ ], particularly in age group of 16 to 44 years; sepsis [OR: 1.45 (95\% CI, $1.21-1.74) ; P<0.001])$, particularly at age more than 45 years; and mortality [OR: 1.14 (95\% CI, 1.01-1.28); $P=0.037$ ]. Prehospital chest tube insertions (214 vs 158) and surgical procedures before intensive care unit admission were more often performed in males ( $79.7 \%$ vs $76.4 \%)$. Females had lower mean hemoglobin levels $[10.7 \pm 2.6 \mathrm{vs} 11.9 \pm 2.8(\mathrm{mg} / \mathrm{dL})]$. There were no sex differences in fluid resuscitation, shock index, coagulation, and base excess.

Conclusions: Males are more susceptible to multiple organ failure, sepsis, and mortality after trauma. Differences were not exclusively related to reproductive age and thus cannot be attributed to sex hormones alone. Females aged 16 to 44 years seem to tolerate shock better. Higher susceptibility to sepsis might be explained by male immune function or increased systemic burden from higher rates of surgical interventions.

Keywords: multiple organ failure, multiple trauma, outcome, sepsis, sex, trauma registry

(Ann Surg 2015;261:774-780)

From the *Institut für Notfallmedizin und Medizinmanagement (INM), Klinikum der Universität München, Munich, Germany; $†$ Institute for Research in Operative Medicine (IFOM), University Witten/Herdecke, Cologne, Germany; $\ddagger$ Academy for Trauma Surgery (AUC), Berlin, Germany; §Klinik für Unfall, Wiederherstellungschirurgie und Orthopädie, Klinikum Memmingen, Germany; and \Department of Surgery, Klinikum der Universität München, Munich, Germany.

Disclosure: TraumaRegister DGU of the Committee on Emergency Medicine, Intensive Care and Trauma Management of the German Trauma Society (Sektion NIS) are the participating investigators. The TraumaRegister DGU functions as scientific advisor and critically reviewed the study proposal. Data was provided by participating TR-DGU trauma centers listed under: http://www.traumaregister.de/index.php?option=com content\&view $=$ article\&id $=48 \&$ Itemid $=54 \&$ lang $=$ en. The authors declare no conflict of interest.

Reprints: Heiko Trentzsch, MD, Institut für Notfallmedizin und Medizinmanagement (INM), Klinikum der Universität München, Schillerstr 53, 80336 Munich, Germany. E-mail: heiko.trentzsch@med.uni-muenchen.de.

Copyright (C) 2014 Wolters Kluwer Health, Inc. All rights reserved.

ISSN: 0003-4932/14/26104-0774

DOI: $10.1097 /$ SLA.0000000000000789
$T_{n}^{h}$ he influence of biological sex has been investigated in numerous studies, including studies in large multicenter trauma databases such as the American College of Surgeon's National Trauma Database. ${ }^{1-17}$ So far, the results have yielded into controversial findings that frequently do not reflect evidence found in experimental models. ${ }^{18-23}$

In humans, it is well known that males and females have different life expectations, comorbidities, and distinct differences in acute and chronic disease manifestation. ${ }^{24}$ It has been shown that females have a more efficient immune system with subsequent improved clinical outcomes after severe infections and circulatory shock. These findings are based on experimental data from animal models suggesting that sex steroids may be responsible for differences in immune function, organ function after traumatic hemorrhage,${ }^{19}$ and survival after abdominal sepsis. ${ }^{18}$ In particular, estrogen is considered to be protective whereas testosterone is considered to have adverse effects. ${ }^{20}$

Evidence of the influence of sex hormones on patient outcomes has been previously documented but has not always been conclusive. Some studies have found that females have lower rates of multiple organ failure (MOF). If ventilator days and intensive care unit (ICU) length of stay were considered surrogate markers of organ failure (OF), some more studies would support the concept of better organ function in females. ${ }^{14-16}$ Others found differences only after stratification by age and injury severity, respectively. For example, Magnotti et $\mathrm{l}^{14}$ have reported that pulmonary failure is diagnosed more often in males [except at less than 40 years of age with an Injury Severity Score (ISS) of $<25$ ], and Oberholzer et a ${ }^{9}$ observed increased rates of MOF only in males when ISS exceeded 25 points. Two studies found neither differences in OF nor acute respiratory distress syndrome and length of ICU stay after major trauma. ${ }^{10,11}$ Although male trauma patients are described to be more susceptible to infectious complications ${ }^{10}$ such as pneumonia ${ }^{13-15}$ and bacteremia, ${ }^{2,14}$ other analyses found no sex difference in rates of infections or sepsis, ${ }^{3,5,11}$ and controversially, there is even 1 study that found more septic complications in females ages 15 to 45 years. ${ }^{8}$

Similar results are found regarding mortality. Some studies report improved survival among premenopausal females, ${ }^{5,8,17}$ whereas others identified postmenopausal women to have better chances of survival. ${ }^{4,6,7,16}$

Although there is substantial data indicating the role of biological sex in clinical course and outcome after major trauma, it remains difficult to decide whether female sex is protective and male sex is detrimental. For instance, many scoring criteria were developed and used to predict mortality after a traumatic event, but these are limited in the fact that biological sex is not included most of the time. Currently, the Trauma Associated Severe Hemorrhage score, ${ }^{25}$ a predictor of the need for massive transfusion after hemorrhagic blunt trauma, is the only score that identified male sex as an independent risk factor. Furthermore, recent studies are largely limited to heterogeneous cohorts in terms of mechanism, age distribution, and injury severity, making them subsequently prone to selection bias. 
The aim of this study was to further elucidate the role of sex on rates of sepsis, MOF, and mortality in patients after major trauma. We hypothesized that examination of a homogenous cohort would control for such bias, thereby eliminating error-prone subgroup analysis. To eliminate the incomparability of male and female groups, we performed a matched pair analysis utilizing TraumaRegister DGU (TR-DGU).

\section{METHODS}

The TR-DGU of the German Trauma Society (Deutsche Gesellschaft für Unfallchirurgie, DGU) is a large, multicenter standardized database. All trauma patients who are admitted through the trauma room of participating trauma centers and who have the probability of ICU treatment are included. At the time of our analysis, TR-DGU contained 29,353 severely injured patients enrolled between 1993 and 2006. TR-DGU data were collected anonymously and according to a previously defined data sheet. Clinical data and laboratory chemical markers (during the prehospital treatment, at emergency department admission, and throughout the hospital course) were collected as referenced on the TR-DGU homepage (www.traumaregister.de).

Inclusion criteria into our study were age 18 years or more and an ISS of 9 or greater. Patients transferred from outside facilities to the treating facility were excluded. Patients were divided in groups by sex and were then matched according to a matching code that was made up from age ( $\leq 15,16-44,45-54,55-64,65-74$, and $\geq 75$ years), exact match of injury severity coded by the Abbreviated Injury Scale (AIS) in 4 body regions (head, thorax, abdomen, and extremities), mechanism (blunt or penetrating), and prehospital presence of shock (systolic blood pressure $\leq 90 \mathrm{~mm} \mathrm{Hg}$ ). Patients with minor injuries of AIS 1 were merged with patients without injury of the specific body region. Because of the small number of AIS 6 injuries to head ( $\mathrm{n}=95,53$ males and 42 females) and thorax ( $\mathrm{n}=9,5$ males and 4 females), these 2 groups were merged with the AIS 5 category.

TR-DGU relies on the following definitions: For each organ, OF is defined by 3 or more points according to Sequential Organ Failure Assessment score. ${ }^{26}$ These criteria are cardiocirculatory system: dopamine more than $5 \mu \mathrm{g} / \mathrm{kg} / \mathrm{min}$ or any Adrenalin-/noradrenalinetreatment; lung: Horowitz-ratio $\left(\mathrm{PaO}_{2} / \mathrm{FiO}_{2}\right)$ less than $200 \mathrm{~mm} \mathrm{Hg}$; kidney: serum-creatinine levels of $3.5 \mathrm{mg} / \mathrm{dL}$ or more or urine output less than $500 \mathrm{~mL} / \mathrm{d}$; liver: bilirubin $6 \mathrm{mg} / \mathrm{dL}$ or more; and coagulation: platelets less than $50,000 / \mathrm{mm}^{3}$. The number of days with $\mathrm{OF}$ is recorded separately for each organ system. MOF is classified as 2 or more failing organ systems for at least 2 consecutive days. The incidence of sepsis in the presence of proven or suspected infection is determined according to the ACCP/SCCM criteria. ${ }^{27}$ Injury severity is determined by the AIS, the ISS, and the New Injury Severity score. The expected mortality at admission is calculated by the Trauma and Injury Severity score ${ }^{28}$ and the Revised Injury Severity Classification score. ${ }^{29}$ Transfusion is defined as any number of units of packed red blood cells (PRBCs) given. Following the traditional definition in accordance with the 2005 United States Army Institute of Surgical Research symposium on early massive transfusion ${ }^{30}$ and international expert opinion, ${ }^{31}$ TR-DGU considers mass transfusion when patients received transfusion of 10 or more units of PRBCs. This amount of units of PRBCs is agreed to be the approximate equivalent of a patient's total blood volume. ${ }^{31}$ Both, transfusion and mass transfusion refer to the number of units or PRBCs given during the time from trauma room admission to ICU admission (mean time: 223 minutes \pm 164 minutes; 95\% confidence interval: 219-227 minutes; median time: 184 minutes). Sepsis-related mortality is defined as death in patients diagnosed with sepsis during initial ICU stay. Preexisting comorbidities are recorded using a standardized list including myocardial infarction (differentiated as $<6$ months ago or $>6$ months ago), unstable angina pectoris, cardiac insufficiency (NYHA III-IV), occlusive arterial disease $\mathrm{IV}^{\circ}$ (by Fontaine), chronic obstructive pulmonary disease, bronchial asthma, diabetes mellitus, terminal renal insufficiency with need for dialysis, chronic renal insufficiency with serum creatinine more than $2.0 \mathrm{mg} / \mathrm{dL}$, inborn or acquired coagulopathy, liver cirrhosis, alcoholism or withdrawal delirium, malignant lymphoma, leukemia, carcinoma with metastatic disease, HIV infection/AIDS, and immunosuppression. There is an opportunity to record additional comorbidities by free-text entry.

For this study, we additionally calculated shock index from heart rate $(\mathrm{bpm}) /$ systolic blood pressure $(\mathrm{mm} \mathrm{Hg})$, shock index of 0.5 to 0.7 was considered physiologic, and an index of greater than 1 was used as a diagnostic shock indicator. ${ }^{32}$

The process of matching was used to generate comparable subsets of cases because of the fact that some variables were not completely documented or have not been recorded over many years.

Data are expressed as mean $\pm \mathrm{SD}$ unless otherwise specified. Statistical analysis was performed by using Student $t$ test or MannWhitney $U$ test, odds ratio (OR) with the respective $95 \%$ confidence interval, absolute risk reduction, and $\chi^{2}$ test where appropriate. The primary outcome data (mortality, sepsis, OF, and MOF) were additionally evaluated using McNemar test for paired data. The marginal loss in power using independent sample statistics instead of paired procedures is neglectable with this large sample size. A $P$ value of less than 0.05 was considered statistically significant although this could result in "significant" differences without clinical relevance. The dimension of the difference should, therefore, be the primary guide for interpretation.

\section{RESULTS}

A total of 20,288 patients primarily admitted to trauma centers participating in the TR-DGU with an ISS of 9 or more were included. Patients were divided by sex, resulting in 14,720 males $(72.6 \%)$ and 5568 females $(27.4 \%)$. In a second step, we matched both groups according to their injury characteristics, resulting in 3887 pairs. Distribution of matching criteria is given in Table 1. Matched groups were similar in baseline characteristics as shown in Table 2. Only the New Injury Severity score showed a significant but clinically nonrelevant difference of 0.7 points $(P=0.035)$. Data on physiological and biochemical markers recorded at admission showed no difference in shock index, base excess, prothrombin time, or partial thrombin time except in hemoglobin as shown in Table 3.

Prehospital interventions such as intubation, analgosedation, catecholamine use, fluid resuscitation, volume replacement, and cardiopulmonary resuscitation did not show significant differences between males and females. A significant difference in prehospital chest tube placement was seen among males $(5.5 \%$ vs $4.1 \%, P=0.003)$. Data are summarized in Table 4.

Treatment data during the acute care phase and during ICU stay are shown in Table 5. Surgical treatment was initiated more often in males than in females $(79.7 \%$ vs $76.4 \% ; P \leq 0.001)$. Males showed a marginally higher mass transfusion rate $(7.4 \%$ vs $6.9 \%, P=0,049)$, longer length of hospital stay in the ICU ( 11 vs 9 days, $P<0.001)$, and a longer duration of mechanical ventilation ( 7 vs 5 days, $P<$ $0.001)$.

With regard to the primary endpoints of the study, females showed lower rates of OF (36.3\% vs $33.1 \%, P=0.005)$, MOF $(20.2 \%$ vs $17.6 \%, P=0.007)$, and sepsis $(9.1 \%$ vs $6.7 \%, P<0.001)$. Using McNemar test, the results were confirmed with respect to mortality $(P=0.014), \operatorname{MOF}(P=0.009)$, and sepsis $(P=0.002)$. Analysis of OF by organ system showed lower rates of circulatory failure (20.2\% vs $17.7 \%, P=0.009)$, lung failure $(19.8 \%$ vs $15.6 \%, P<$ $0.001)$, and renal failure $(4.6 \%$ vs $3.1 \%, P=0.002)$ among females. There were no differences in $\mathrm{OF}$ with regard to coagulation or liver 
TABLE 1. Distribution of Matching Criteria in Both Subgroups of 3887 Pairs

\begin{tabular}{|c|c|c|}
\hline Criterion & Strata & $\%$ \\
\hline Age group & $\begin{array}{c}\leq 15 \mathrm{yr} \\
16-44 \mathrm{yr} \\
45-54 \mathrm{yr} \\
55-64 \mathrm{yr} \\
65-74 \mathrm{yr} \\
\geq 75 \mathrm{yr}\end{array}$ & $\begin{array}{r}5.3 \\
53.7 \\
11.1 \\
10.2 \\
8.7 \\
10.9\end{array}$ \\
\hline Head injury & $\begin{array}{c}\text { AIS 0/1 } \\
\text { AIS } 2 \\
\text { AIS } 3 \\
\text { AIS } 4 \\
\text { AIS 5/6 }\end{array}$ & $\begin{array}{l}35.2 \\
14.3 \\
13.2 \\
20.3 \\
16.9\end{array}$ \\
\hline Chest injury & $\begin{array}{c}\text { AIS 0/1 } \\
\text { AIS } 2 \\
\text { AIS } 3 \\
\text { AIS } 4 \\
\text { AIS 5/6 }\end{array}$ & $\begin{array}{r}51.1 \\
3.3 \\
21.5 \\
18.2 \\
6.0\end{array}$ \\
\hline Abdominal injury & $\begin{array}{c}\text { AIS 0/1 } \\
\text { AIS } 2 \\
\text { AIS } 3 \\
\text { AIS } 4 \\
\text { AIS 5/6 }\end{array}$ & $\begin{array}{r}75.3 \\
8.4 \\
9.2 \\
4.7 \\
2.4\end{array}$ \\
\hline Injury of extremities & $\begin{array}{c}\text { AIS 0/1 } \\
\text { AIS } 2 \\
\text { AIS } 3 \\
\text { AIS } 4 \\
\text { AIS 5/6 }\end{array}$ & $\begin{array}{r}36.2 \\
24.4 \\
32.0 \\
5.3 \\
2.1\end{array}$ \\
\hline Mechanism of injury & $\begin{array}{c}\text { Blunt } \\
\text { Penetrating }\end{array}$ & $\begin{array}{r}97.7 \\
2.3\end{array}$ \\
\hline Prehospital shock & $\begin{array}{l}\text { Yes } \\
\text { No }\end{array}$ & $\begin{array}{l}19.2 \\
80.8\end{array}$ \\
\hline
\end{tabular}

\section{TABLE 2. Baseline Data}

\begin{tabular}{lccc}
\hline Baseline Data & Males & Females & $\boldsymbol{P}$ \\
\hline Age, yr & $42.6 \pm 21.3$ & $42.4 \pm 21.8$ & 0.723 \\
ISS (points) & 39 & 39 & \\
& $24.9 \pm 13.1$ & $24.6 \pm 12.8$ & 0.429 \\
NISS (points) & 22 & 22 & \\
& $31.2 \pm 15.4$ & $30.5 \pm 15.2$ & 0.035 \\
Prehospital shock index (HR/SBP) & $0.84 \pm 0.41$ & $0.86 \pm 0.38$ & 0.054 \\
& 0.75 & 0.78 & \\
Comorbidities, \% & 25.9 & 27.6 & 0.089 \\
Expected mortality by TRISS, \% & 19.3 & 18.7 & 0.407 \\
Expected mortality by RISC, \% & 17.2 & 17.4 & 0.842 \\
\hline
\end{tabular}

Continuous variables presented as mean $\pm \mathrm{SD}$, median.

HR indicates heart rate; NISS, New Injury Severity score; RISC, Revised Injury Severity Classification; SBP, systolic blood pressure; TRISS, Trauma and Injury Severity score.

function. Females had lower mortality than males (17.8\% vs $16.1 \%$, $P=0.037$ ). Patients diagnosed with sepsis during ICU stay showed no difference in mortality $(21.8 \%$ vs $18.3 \%, P=0.330)$. Outcome data are summarized in Table 6.

After age stratification, the rate of MOF in females was significantly lower at 16 to 45 years than that in males $(16.8 \%$ vs $14.2 \%$, $P=0.027$; Fig. 1A). Past 45 years of age, MOF rates became similar in both groups. With regard to sepsis, females aged 45 to 74 years
TABLE 3. Physiological and Biochemical Data on Hospital Admission

\begin{tabular}{lccc}
\hline & Males & Females & $\boldsymbol{P}$ \\
\hline Shock index (HR/SBP) & $0.79 \pm 0.36$ & $0.79 \pm 0.40$ & 0.761 \\
& 0.71 & 0.72 & \\
Hemoglobin, mg/dL & $11.9 \pm 2.8$ & $10.7 \pm 2.6$ & $<0.001$ \\
& 12.3 & 11.0 & \\
Base excess, mmol/L & $-3.0 \pm 5.0$ & $-3.3 \pm 4.8$ & 0.064 \\
& -2.4 & -2.8 & \\
Prothrombin time, \% & $79.4 \pm 23.1$ & $79.3 \pm 23.1$ & 0.912 \\
& 84 & 84 & \\
Partial thromboplastin time, $\mathrm{s}$ & $34.9 \pm 19.2$ & $35.9 \pm 20.4$ & 0.107 \\
& 30 & 31 & \\
\hline
\end{tabular}

Continuous variables presented as mean $t$ standard deviation, median.

HR indicates heart rate; NISS, New Injury Severity score; RISC, Revised Injury Severity Classification; SBP, systolic blood pressure; TRISS, Trauma and Injury Severity score.

had a lower risk for sepsis with an absolute risk reduction of about $3 \%$ to $5 \%$ than males (Fig. 1B). A statistically significant difference in mortality was observed in the age group of 16 to 44 years with McNemar test $(P=0.035)$ but not with $\chi^{2}$ test $(P=0.069$; Fig. $1 C)$.

\section{DISCUSSION}

Based on animal models, it has been stated that female sex is protective with lower rates of sepsis and less MOF and male sex is associated with an adverse outcome. ${ }^{18-23}$ To date, at least 17 epidemiological studies (exclusive of studies analyzing specific injuries such as spinal cord injury, neurotrauma, or burns) with more than 300,000 patients have analyzed sex differences in the response to severe trauma. ${ }^{1-17}$ Despite this large body of research, the results remain controversial, because clinical observations frequently do not reflect the conclusions drawn from experimental data. One possible explanation for the discrepancies may be that those clinical studies looked at inappropriate trauma cohorts with a low risk for adverse outcome. For example, low injury severity will yield into low risk of complication such as MOF or sepsis. Actually, half of the studies on sex differences in trauma outcome ${ }^{1,2,4,5,13-17}$ analyzed cohorts with a mean ISS less than 16 points (range, 7-14). Thus, these cohorts are unlikely to experience considerable mortality rates. Two-thirds of the studies $1,2,4,5,7,9-11,13-17$ analyzed cohorts with a mortality rate not exceeding $10 \%$ (range, $1.9 \%-9.7 \%$ ). Just $3^{3,8,12}$ of 17 studies have provided data with more authentic mortality rates $(20.1 \%, 14.8 \%$, and $14.0 \%$, respectively). In our study, we observed a mean ISS of 25 points and a mortality rate of about $17 \%$. Thus, our population has a considerable risk for the selected endpoints (septic complications, MOF, and death) to facilitate proper analysis.

Furthermore, many of the study cohorts cited previously seem to be heterogeneous. There are discrepancies concerning age, ${ }^{9,10,17}$ injury severity ${ }^{8,10}$ glasgow coma scale and revised trauma score, ${ }^{11}$ mechanism, ${ }^{2}$ or distribution of comorbidities, ${ }^{4}$ and this may explain why many studies ${ }^{1-5,9,11,13-17}$ had to use test of interaction to detect sex differences. However, this approach is prone to error and, therefore, confusing results are no surprise. We elected to examine sex-related differences after major trauma, using matched pair analysis to create a homogeneous study population of males and females to avoid some of the aforementioned methodological flaws. To date, there has been only 1 other matched pair analysis on sex differences after trauma. ${ }^{11}$ In this particular study, however, matching criteria were limited to AIS score of head and abdomen but did not include age. It comes to no surprise that no sex differences were observed at all. Obviously, age must be considered when examining sex-related 


\section{TABLE 4. Data on Prehospital Treatment}

\begin{tabular}{|c|c|c|c|c|}
\hline & Males & Females & $\begin{array}{c}\text { OR (95\% } \\
\text { Confidence Interval) }\end{array}$ & $\boldsymbol{P}$ \\
\hline Intubation, \% & 54.4 & 55.1 & $0.97(0.89-1.06)$ & 0.518 \\
\hline Chest tube insertion, $\%$ & 5.5 & 4.1 & $1.37(1.11-1.69)$ & 0.003 \\
\hline Catecholamine, $\%$ & 7.3 & 7.0 & $1.08(0.87-1.23)$ & 0.667 \\
\hline Fluid resuscitation, $\%$ & 92.8 & 92.8 & $1.00(0.85-1.19)$ & 0.971 \\
\hline Volume administered, $\mathrm{mL}$ & $\begin{array}{c}1399 \pm 1112 \\
1000\end{array}$ & $\begin{array}{c}1355 \pm 1055 \\
1000\end{array}$ & $\mathrm{n} / \mathrm{a}$ & 0.077 \\
\hline Cardiopulmonary resuscitation, $\%$ & 3.0 & 2.7 & $1.11(0.85-1.44)$ & 0.462 \\
\hline Analgosedation, $\%$ & 80.1 & 79.2 & $1.06(0.95-1.18)$ & 0.322 \\
\hline
\end{tabular}

Continuous variables presented as mean $\pm \mathrm{SD}$, median.

$\mathrm{n} / \mathrm{a}$ indicates not applicable.

TABLE 5. Data on Hospital Treatment

\begin{tabular}{|c|c|c|c|c|}
\hline & Males & Females & $\begin{array}{c}\text { OR }(95 \% \\
\text { Confidence Interval) }\end{array}$ & $\boldsymbol{P}$ \\
\hline Chest tube insertion in ER, \% & 18.8 & 17.9 & $1.07(0.95-1.20)$ & 0.289 \\
\hline Catecholamines until admission to ICU, \% & 19.9 & 18.8 & $1.07(0.96-1.20)$ & 0.242 \\
\hline Surgical procedures performed until admission to ICU, \% & 79.7 & 76.4 & $1.22(1.09-1.35)$ & $<0.001$ \\
\hline Life-saving, emergency surgical procedures, $\%$ & 6.6 & 7.7 & $0.843(0.71-1.002)$ & 0.052 \\
\hline Volume administered until admission to ICU, $\mathrm{mL}$ & $\begin{array}{c}2626 \pm 2585 \\
2000\end{array}$ & $\begin{array}{c}2618 \pm 2681 \\
2000\end{array}$ & $\mathrm{n} / \mathrm{a}$ & 0.901 \\
\hline Transfusion rate, $\%$ & 27.7 & 29.6 & $0.91(0.83-1.01)$ & 0.067 \\
\hline Mass transfusion rate, $\%$ & 7.4 & 6.9 & $1.07(0.90-1.27)$ & 0.469 \\
\hline Lactate levels upon ICU admission, mg/dL & $\begin{array}{c}3.0 \pm 3.8 \\
2.1\end{array}$ & $\begin{array}{c}3.0 \pm 4.3 \\
2.1\end{array}$ & $\mathrm{n} / \mathrm{a}$ & 0.763 \\
\hline ICU length of stay, $d$ & $\begin{array}{c}11.0 \pm 13.4 \\
6\end{array}$ & $\begin{array}{c}9.3 \pm 11.6 \\
5\end{array}$ & $\mathrm{n} / \mathrm{a}$ & $<0.001$ \\
\hline Length of mechanical ventilation, $d$ & $\begin{array}{c}7.0 \pm 10.9 \\
2\end{array}$ & $\begin{array}{c}5.6 \pm 9.6 \\
2\end{array}$ & $\mathrm{n} / \mathrm{a}$ & $<0.001$ \\
\hline Length of hospital stay, d & $\begin{array}{c}25.7 \pm 27.5 \\
19\end{array}$ & $\begin{array}{c}24.9 \pm 26.8 \\
18\end{array}$ & $\mathrm{n} / \mathrm{a}$ & 0.209 \\
\hline
\end{tabular}

Continuous variables presented as mean $\pm \mathrm{SD}$, median.

$\mathrm{n} / \mathrm{a}$ indicates not applicable.

\section{TABLE 6. Outcome Data}

\begin{tabular}{|c|c|c|c|c|}
\hline & Males & Females & $\begin{array}{c}\text { OR }(95 \% \\
\text { Confidence Interval) }\end{array}$ & $P\left(\chi^{2}\right)$ \\
\hline Organ failure $(\mathrm{OF}, \%)$ & 36.3 & 33.1 & $1.15(1.05-1.27)$ & 0.005 \\
\hline OF circulation, $\%$ & 20.2 & 17.7 & $1.17(1.04-1.33)$ & 0.009 \\
\hline OF lung, $\%$ & 19.8 & 15.6 & $1.33(1.17-1.51)$ & $<0.001$ \\
\hline OF kidney, $\%$ & 4.6 & 3.1 & $1.41(1.16-1.91)$ & 0.002 \\
\hline OF coagulation, $\%$ & 5.6 & 5.2 & $1.09(0.88-1.34)$ & 0.441 \\
\hline OF liver, $\%$ & 3.4 & 3.4 & $0.99(0.76-1.28)$ & 0.918 \\
\hline MOF, $\%$ & 20.2 & 17.6 & $1.18(1.05-1.33)$ & 0.007 \\
\hline Sepsis, $\%$ & 9.3 & 6.6 & $1.45(1.21-1.74)$ & $<0.001$ \\
\hline Mortality (overall, \%) & 17.8 & 16.1 & $1.14(1.01-1.28)$ & 0.037 \\
\hline Mortality (in patients diagnosed with sepsis, \%) & 21.8 & 18.3 & $1.25(0.80-1.94)$ & 0.330 \\
\hline
\end{tabular}

differences due to the possible effect of sex hormones, specifically in premenopausal and postmenopausal patient populations.

Our study population of 3887 pairs matched for age, mechanism, and pattern of injury seems to fulfill the desired homogeneity except from a minor, however, statistically significant difference of less than 1 point in injury severity. We do not consider this difference to be of any clinical relevance because there was an exact match of AIS injury severity in the 4 major body regions. Thus, we managed to investigate sex differences within a large and well-defined, homogenous cohort of male and female trauma patients who suffered substantial degree of injury and moreover have a considerable risk to develop adverse events throughout their clinical course.

We observed reduced rates of OF in females, particularly in those organ systems prone to shock such as lung and kidney. This finding is in accordance with other studies. ${ }^{3,12}$ However, sex differences often were found only by test of interaction within specific subgroups or after post hoc stratification of the data. ${ }^{5,8,9,14}$ George et $\mathrm{al}^{5}$ reported higher rates of renal failure in males after blunt trauma 

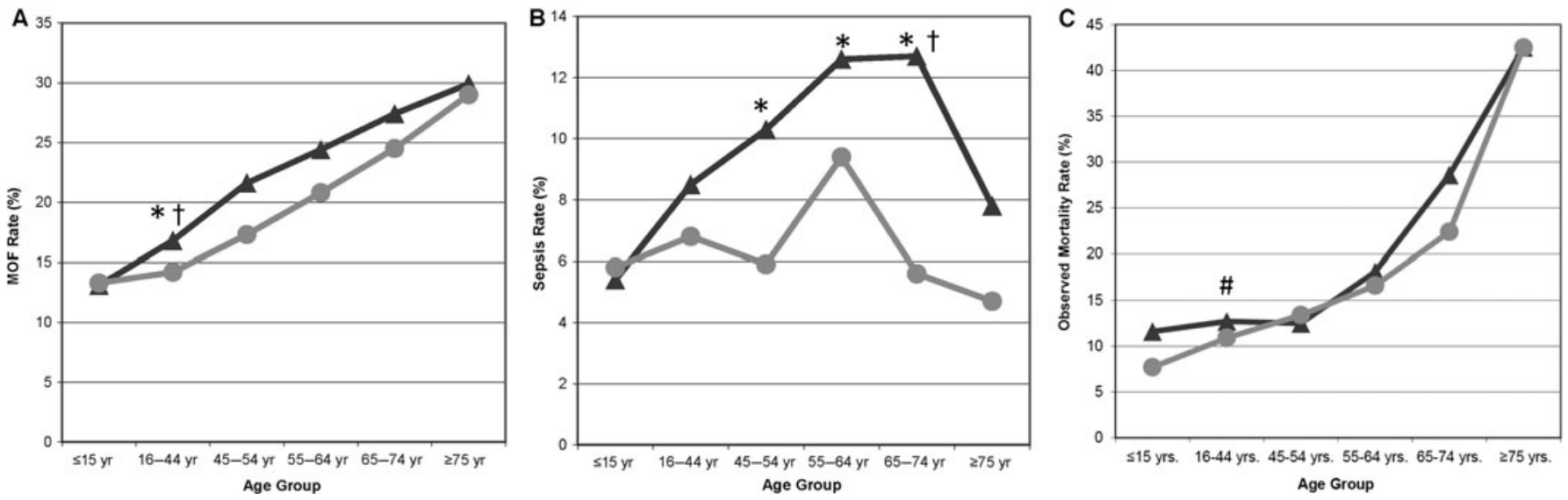

FIGURE 1. A-C, Graph shows rates of (A) MOF, (B) sepsis, and (C) mortality of male and female patients stratified by the designated age groups. Results for the subgroup of males are depicted as dark gray triangles, whereas results for females are depicted as light gray circles. Significant differences between the groups $(P<0.05)$ are indicated by * for $\chi^{2}$ test, and by $\dagger$ for McNemar test.

but no difference in pulmonary failure. Shock is known as an independent risk factor for MOF after major trauma. ${ }^{33} \mathrm{Clinical}^{33-35}$ and experimental ${ }^{36}$ data indicate that females, due to the effects of female sex steroids such as 17- $\beta$-estradiol, are more resistant to shock. Direct effects of sex steroids and sex differences in cardiovascular function have previously been described in detail. ${ }^{37-39}$ The improved cardiovascular function in females may be responsible for the lower rates of OF observed. Following age stratification, the significant difference in MOF rates was restricted to the age group of 16 to 44 years. Similar findings were described by Mostafa et al, ${ }^{8}$ whose data also support the influence of sex steroids, showing lower OF in females at the age of 15 to 45 years. Reproductive age and sex hormones may play a protective role, thereby resulting in lower rates of $\mathrm{OF}$ among females.

Males had an increased susceptibility toward infectious complications and increased rates of sepsis as compared with females. Several clinical studies support this finding ${ }^{2,3,9}$ and indicated that male sex is an independent risk factor for sepsis. ${ }^{40}$ Higher rates of infectious complications, ${ }^{10}$ urinary tract infections, ${ }^{5}$ and pneumonia ${ }^{2,15}$ in males after major trauma have been described. The immune dysfunction observed after trauma leads to diminished host defense and an increased susceptibility to nosocomial infections and severe sepsis. In animal models, this dysfunction can be modulated by sex steroids. $^{21,22}$ Surgical castration and pharmacological testosterone blockade in mice have been shown to improve immune function after trauma-hemorrhage and outcome after sepsis. ${ }^{19,23}$ In humans, it seems as if males have a more pronounced response with increased levels of interleukin (IL)- 6 and IL-8 than females. ${ }^{3,9,41}$ When our data were stratified by age, we found that statistically significant differences were observed particularly in the age groups of 45 to 54,55 to 54 , and 65 to 74 years. By definition, females at this age are considered to be in menopause, where plasma levels of female sex steroid decline. ${ }^{42}$ In males, however, the increase in susceptibility to sepsis is first observed at the age when there is an increase in testosterone production (ie, age group: 16-44 years) and is preserved throughout all further age groups, although not all subgroups meet the designated level of significance. In contrast to females, males maintain more or less constant testosterone levels throughout their life span, with a slow decline toward senescence. ${ }^{43}$ Consequently, our data support the hypothesis that increased susceptibility to infectious complications and sepsis is likely associated with androgens. ${ }^{18-23}$
With increased risk of OF/MOF and sepsis, we expected that males would have increased mortality rates. There are authors who have detected lower mortality rates in females at a reproductive age $\mathrm{a}^{5,8,17}$ and who causally linked these observations to sex steroids. Other studies ${ }^{4,6,7,16}$ reported better survival in females older than 50 years only. In our study, females had an absolute reduction in mortality by $1.7 \%$. The odds of dying were 1.14 times higher for males than for females $\left(P=0.037\right.$ using $\chi^{2}$ test and $P=0.014$ using McNemar test). When mortality was stratified by age groups, we observed a significant difference in the age group of 16 to 44 years in accordance with our MOF data and may indicate an association with sex steroids. However, this difference reached statistical significance only with McNemar test. Hence, this difference has to be considered with caution. The probability of a type 1 error in this analysis was $3.7 \%$ when using the $\chi^{2}$ test on overall mortality rates. Because of the large number of individuals included into this study, this significant difference in mortality might be by chance.

There are several observations that support the protective role of estrogen. However, plasma estrogen levels have repeatedly been observed to markedly increase in critically ill patients under stressful conditions such as blunt trauma, ${ }^{44}$ major abdominal surgery, ${ }^{45}$ surgical sepsis, ${ }^{46}$ and septic shock. ${ }^{47-49}$ Actually, peaks in estrogen plasma levels exceeding $50 \mathrm{pg} / \mathrm{mL}$ predict mortality in the critically ill. ${ }^{50}$ Moreover, this is an amount of estrogen that is far below physiologic estrogen levels in sexually mature females. Sex hormones function as steroid hormones via genomic and membrane-initiated steroid signaling. ${ }^{51}$ It comes to no surprise that they exert potent effects on immune function or the vasculature. Experimental studies suggest that genetic variability does modulate the individual's response to such hormone-driven effects. ${ }^{52}$ Such variability thus may explain these somewhat paradoxical observations.

Sex-specific variation in the genetic makeup may indeed add another possible factor contributing to sex-related differences. Although the male $\mathrm{Y}$ chromosome seems to be genetic wasteland, many of the 1200 genes residing on the $\mathrm{X}$ chromosome play a role in the innate immune response including several protein members of the toll-like receptor signaling cascade, the toll-like receptor, NF-kB signaling machinery, genes for IL-1 receptor-associated kinase 1 (IRAK-1), IL-2 receptor $\gamma$, IL-13 receptor $\alpha 2$, and the NFkB-essential modulator NEMO, which is a crucial transcription factor regulating infection-associated cellular stress responses, cytokine production, cell proliferation, apoptosis, and necrosis. ${ }^{53,54} \mathrm{~A}$ 
number of experimental studies support the hypothesis of a link between the $\mathrm{X}$ chromosome and the inflammatory response. ${ }^{55,56}$ Our database does not include genetic information. Further study is warranted.

Moreover, sex-related differences may be the result of unconscious and unintentional differences in the management of female versus male trauma patients. One study found that female trauma patients with severe shock required lower volumes of lactated ringers during shock-trauma resuscitation to maintain a designated oxygen transport capacity in comparison with equally injured males. ${ }^{33}$ In fact, the amount of crystalloid solutions given during the first 4 hours was even, but males would require higher volumes of maintenance fluid throughout the 24-hour course of the observational period. The authors concluded that female hearts respond better to resuscitation efforts. The ratio of fluid volume to body weight was not reported. In our study, we found no difference in the volume of administered resuscitation fluids. However, a few matched pairs with data on size and body weight were available (not shown). Because the numbers were insufficient for statistical analysis, we can just estimate that females may have received about $600 \mathrm{~mL}$ more intravenous fluids than males until ICU admission relative to their average body weight. Therefore, unintentional differences in the physiognomy of males and females may affect treatment that result in a treatment bias. Further research is required to prove this hypothesis.

We also found that males underwent higher rate of surgical procedures performed in the early phase after hospital admission despite matching for injury pattern. Differences in New Injury Severity score cannot explain this observation. These interventions may have caused increased systemic burden in addition to traumatic stress. Pape et $\mathrm{al}^{57}$ found that surgical procedures during the early phase after trauma are associated with increased risk of MOF. This observation supports the higher OF/MOF rates observed in males in our study. Unfortunately, the structure of the database does not allow us to scrutinize the underlying injuries that brought males into the operating room and if similar injuries were left treated nonsurgically in females. Moreover, males underwent significantly higher rates of mass transfusion. Male sex is known as an independent risk factor for risk of massive transfusion as described by the Trauma Associated Severe Hemorrhage score. ${ }^{25}$ It might be that males more often suffered injuries that are associated with a higher risk of severe bleeding. This would explain higher need for surgical intervention, too. However, AIS scores for chest, abdomen, and extremities, which contain most injuries with increased risk of bleeding, were used for matching and thus this possible bias should have been controlled.

The major limitation of this study is that there is no information provided on the hormonal status. To draw more valid conclusions, clinical data on the phase of the menstrual cycle, plasma hormone levels, and medication such as hormone replacement therapy, sex steroid antagonists, or aromatase inhibitors would be needed. Because of the lack of such data, menopause and reproductive age were assigned to patients by definition and not on the basis of prospectively collected patient data. Our findings clearly demonstrate that female patients have a significantly lower risk for the development of OF, MOF, and sepsis after major trauma. We conclude that female organ function is more stable in response to shock and its consequences and that male sex leads to increased risk for sepsis. It also seems as if females may have better rates of survival but due to large sample size, there is some chance left that this observation might be by chance.

This observation was made on the premises of a homogenous cohort controlled for age group and injury severity by the use of matched pair analysis. Increased risk for MOF, sepsis, and mortality may be attributable to effects of sex hormones. However, our data cannot confirm any hypothesis of underlying mechanism, undoubtedly.

\section{CONCLUSIONS}

Our results confirm observations on sex differences observed in experimental models and thus ensure the appraisal that biological sex plays an important clinical role in the response to major trauma. Further research is needed to determine the mechanism behind these differences to improve patient care that might lead to different treatment approaches for either males or females.

\section{ACKNOWLEDGMENT}

The authors thank Katrina Kraft, MD, for the critical review of the manuscript.

\section{REFERENCES}

1. Bowles BJ, Roth B, Demetriades D. Sexual dimorphism in trauma? A retrospective evaluation of outcome. Injury. 2003;34:27-31.

2. Croce MA, Fabian TC, Malhotra AK, et al. Does gender difference influence outcome? J Trauma. 2002;53:889-894.

3. Frink M, Pape HC, van Griensven M, et al. Influence of sex and age on mods and cytokines after multiple injuries. Shock. 2007;27:151-156.

4. George RL, McGwin G, Jr, Metzger J, et al. The association between gender and mortality among trauma patients as modified by age. J Trauma. 2003;54:464 471.

5. George RL, McGwin G, Jr, Windham ST, et al. Age-related gender differential in outcome after blunt or penetrating trauma. Shock. 2003;19:28-32.

6. Knudson MM, Lieberman J, Morris JA, Jr, et al. Mortality factors in geriatric blunt trauma patients. Arch Surg. 1994;129:448-453.

7. Morris JA, Jr, MacKenzie EJ, Damiano AM, et al. Mortality in trauma patients: the interaction between host factors and severity. J Trauma. 1990;30:14761482 .

8. Mostafa G, Huynh T, Sing RF, et al. Gender-related outcomes in trauma. $J$ Trauma. 2002;53:430-434; discussion 434-435.

9. Oberholzer A, Keel M, Zellweger R, et al. Incidence of septic complications and multiple organ failure in severely injured patients is sex specific. J Trauma. 2000;48:932-937.

10. Offner PJ, Moore EE, Biffl WL. Male gender is a risk factor for major infections after surgery. Arch Surg. 1999;134:935-938; discussion 938-940.

11. Rappold JF, Coimbra R, Hoyt DB, et al. Female gender does not protect blunt trauma patients from complications and mortality. J Trauma. 2002;53:436441; discussion 441.

12. Sperry JL, Nathens AB, Frankel HL, et al. Characterization of the gender dimorphism after injury and hemorrhagic shock: are hormonal differences responsible? Crit Care Med. 2008;36:1838-1845.

13. Gannon CJ, Pasquale M, Tracy JK, et al. Male gender is associated with increased risk for postinjury pneumonia. Shock. 2004;21:410-414.

14. Magnotti LJ, Fischer PE, Zarzaur BL, et al. Impact of gender on outcomes after blunt injury: a definitive analysis of more than 36,000 trauma patients. $J$ Am Coll Surg. 2008;206:984-991; discussion 991-982.

15. Napolitano LM, Greco ME, Rodriguez A, et al. Gender differences in adverse outcomes after blunt trauma. J Trauma. 2001;50:274-280.

16. Taylor MD, Tracy JK, Meyer W, et al. Trauma in the elderly: intensive care unit resource use and outcome. J Trauma. 2002;53:407-414.

17. Wohltmann CD, Franklin GA, Boaz PW, et al. A multicenter evaluation of whether gender dimorphism affects survival after trauma. Am J Surg. 2001;181:297-300

18. Zellweger R, Wichmann MW, Ayala A, et al. Females in proestrus state maintain splenic immune functions and tolerate sepsis better than males. Crit Care Med. 1997;25:106-110.

19. Wichmann MW, Zellweger R, DeMaso CM, et al. Mechanism of immunosuppression in males following trauma-hemorrhage. Critical role of testosterone. Arch Surg. 1996;131:1186-1191; discussion 1191-1182.

20. Raju R, Chaudry IH. Sex steroids/receptor antagonist: their use as adjuncts after trauma-hemorrhage for improving immune/cardiovascular responses and for decreasing mortality from subsequent sepsis. Anesth Analg. 2008;107:159 166.

21. Choudhry MA, Bland KI, Chaudry IH. Trauma and immune response-effect of gender differences. Injury. 2007;38:1382-1391.

22. Choudhry MA, Bland KI, Chaudry IH. Gender and susceptibility to sepsis following trauma. Endocr Metab Immune Disord Drug Targets. 2006;6:127135 . 
23. Angele MK, Wichmann MW, Ayala A, et al. Testosterone receptor blockade after hemorrhage in males. Restoration of the depressed immune functions and improved survival following subsequent sepsis. Arch Surg. 1997;132:12071214.

24. Pinn VW. Sex and gender factors in medical studies: implications for health and clinical practice. JAMA. 2003;289:397-400.

25. Maegele M, Lefering R, Wafaisade A, et al. Revalidation and update of the TASH-Score: a scoring system to predict the probability for massive transfusion as a surrogate for life-threatening haemorrhage after severe injury. Vox Sang. 2011;100:231-238.

26. Vincent JL, Moreno R, Takala J, et al. The SOFA (Sepsis-Related Organ Failure Assessment) score to describe organ dysfunction/failure. On behalf of the Working Group on Sepsis-Related Problems of the European Society of Intensive Care Medicine. Intensive Care Med. 1996;22:707-710.

27. Bone RC, Balk RA, Cerra FB, et al. Definitions for sepsis and organ failure and guidelines for the use of innovative therapies in sepsis. The ACCP/SCCM Consensus Conference Committee. American College of Chest Physicians/Society of Critical Care Medicine. Chest. 1992;101:1644-1655.

28. Champion HR, Sacco WJ, Hunt TK. Trauma severity scoring to predict mortality. World J Surg. 1983;7:4-11.

29. Lefering R. Development and validation of the revised injury severity classification score for severely injured patients. Eur J Trauma Emerg Surg. 2009;35:437-447.

30. Malone DL, Hess JR, Fingerhut A. Massive transfusion practices around the globe and a suggestion for a common massive transfusion protocol. J Trauma. 2006;60:S91-S96.

31. Levi M, Fries D, Gombotz H, et al. Prevention and treatment of coagulopathy in patients receiving massive transfusions. Vox Sang. 2011;101:154-174.

32. Vandromme MJ, Griffin RL, Kerby JD, et al. Identifying risk for massive transfusion in the relatively normotensive patient: utility of the prehospital shock index. J Trauma. 2011;70:384-388; discussion 388-390.

33. McKinley BA, Kozar RA, Cocanour CS, et al. Standardized trauma resuscitation: female hearts respond better. Arch Surg. 2002;137:578-583; discussion 583-574.

34. Haider AH, Crompton JG, Chang DC, et al. Evidence of hormonal basis for improved survival among females with trauma-associated shock: an analysis of the National Trauma Data Bank. J Trauma. 2010;69:537-540.

35. Deitch EA, Livingston DH, Lavery RF, et al. Hormonally active women tolerate shock-trauma better than do men: a prospective study of over 4000 trauma patients. Ann Surg. 2007;246:447-453; discussion 453-445.

36. Mizushima Y, Wang P, Jarrar D, et al. Estradiol administration after traumahemorrhage improves cardiovascular and hepatocellular functions in male animals. Ann Surg. 2000;232:673-679.

37. Ba ZF, Kuebler JF, Rue LW, III, et al. Gender dimorphic tissue perfusion response after acute hemorrhage and resuscitation: role of vascular endothelial cell function. Am J Physiol Heart Circ Physiol. 2003;284:H2162H2169.

38. Childs EW, Tharakan B, Hunter FA, et al. 17 beta-estradiol mediated protection against vascular leak after hemorrhagic shock: role of estrogen receptors and apoptotic signaling. Shock. 2010;34:229-235.

39. Hayward CS, Kelly RP, Collins P. The roles of gender, the menopause and hormone replacement on cardiovascular function. Cardiovasc Res. 2000;46:28-49.
40. Wafaisade A, Lefering R, Bouillon B, et al. Epidemiology and risk factors of sepsis after multiple trauma: an analysis of 29,829 patients from the Trauma Registry of the German Society for Trauma Surgery. Crit Care Med. 2011;39:621-628.

41. Sperry JL, Friese RS, Frankel HL, et al. Male gender is associated with excessive IL-6 expression following severe injury. J Trauma. 2008;64:572-578; discussion 578-579.

42. Burger HG, Hale GE, Robertson DM, et al. A review of hormonal changes during the menopausal transition: focus on findings from the Melbourne Women's Midlife Health Project. Hum Reprod Update. 2007;13:559-565.

43. Starka L, Pospisilova H, Hill M. Free testosterone and free dihydrotestosterone throughout the life span of men. J Steroid Biochem Mol Biol. 2009;116:118 120

44. Majetschak M, Christensen B, Obertacke U, et al. Sex differences in posttraumatic cytokine release of endotoxin-stimulated whole blood: relationship to the development of severe sepsis. J Trauma. 2000;48:832-839; discussion 839-840.

45. Scheingraber S, Dobbert D, Schmiedel P, et al. Gender-specific differences in sex hormones and cytokines in patients undergoing major abdominal surgery. Surg Today. 2005;35:846-854.

46. Schroder J, Kahlke V, Staubach KH, et al. Gender differences in human sepsis Arch Surg. 1998;133:1200-1205.

47. Christeff N, Benassayag C, Carli-Vielle C, et al. Elevated oestrogen and reduced testosterone levels in the serum of male septic shock patients. J Steroid Biochem. 1988;29:435-440.

48. Christeff N, Carli A, Benassayag C, et al. Relationship between changes in serum estrone levels and outcome in human males with septic shock. Circ Shock. 1992;36:249-255.

49. Fourrier F, Jallot A, Leclerc L, et al. Sex steroid hormones in circulatory shock, sepsis syndrome, and septic shock. Circ Shock. 1994;43:171-178.

50. Dossett LA, Swenson BR, Evans HL, et al. Serum estradiol concentration as a predictor of death in critically ill and injured adults. Surg Infect (Larchmt). 2008;9:41-48.

51. Yu HP, Chaudry IH. The role of estrogen and receptor agonists in maintaining organ function after trauma-hemorrhage. Shock. 2009;31:227-237.

52. Trentzsch H, Stewart D, De Maio A. Genetic background conditions the effect of sex steroids on the inflammatory response during endotoxic shock. Crit Care Med. 2003;31:232-236.

53. Ross MT, Grafham DV, Coffey AJ, et al. The DNA sequence of the human X chromosome. Nature. 2005;434:325-337.

54. Spolarics Z. The X-files of inflammation: cellular mosaicism of X-linked polymorphic genes and the female advantage in the host response to injury and infection. Shock. 2007;27:597-604.

55. Torres MB, Trentzsch H, Stewart D, et al. Protection from lethal endotoxic shock after testosterone depletion is linked to chromosome X. Shock $2005 ; 24: 318-323$

56. Chandra R, Federici S, Hasko G, et al. Female X-chromosome mosaicism for gp91phox expression diversifies leukocyte responses during endotoxemia. Crit Care Med. 2010;38:2003-2010.

57. Pape H, Stalp M, Griensven MV, et al. [Optimal timing for secondary surgery in polytrauma patients: an evaluation of 4,314 serious-injury cases]. Chirurg. 1999; 70:1287-1293. 